\title{
Article \\ A Short-Cut Data Mining Method for the Mass Spectrometric Characterization of Block Copolymers
}

\author{
Ákos Kuki ${ }^{1}$, Gergó Róth ${ }^{1,2}$, Anna Nagy ${ }^{1}$, Miklós Zsuga ${ }^{1}$, Sándor Kéki ${ }^{1}\left[\right.$ and Tibor Nagy ${ }^{1, *}$ (D) \\ 1 Department of Applied Chemistry, Faculty of Science and Technology, University of Debrecen, Egyetem tér 1, \\ H-4032 Debrecen, Hungary; kuki.akos@science.unideb.hu (Á.K.); roth.gergo@science.unideb.hu (G.R.); \\ nagy.anna26@gmail.com (A.N.); zsuga.miklos@science.unideb.hu (M.Z.); \\ keki.sandor@science.unideb.hu (S.K.) \\ 2 Doctoral School of Chemistry, University of Debrecen, Egyetem tér 1, H-4032 Debrecen, Hungary \\ * Correspondence: nagy.tibor@science.unideb.hu; Fax: +36-52-518662
}

check for updates

Citation: Kuki, Á.; Róth, G.; Nagy, A.;

Zsuga, M.; Kéki, S.; Nagy, T. A

Short-Cut Data Mining Method for

the Mass Spectrometric

Characterization of Block

Copolymers. Processes 2022, 10, 42. https://doi.org/10.3390/pr10010042

Academic Editor: Antonino Recca

Received: 9 December 2021

Accepted: 22 December 2021

Published: 27 December 2021

Publisher's Note: MDPI stays neutral with regard to jurisdictional claims in published maps and institutional affiliations.

Copyright: (C) 2021 by the authors. Licensee MDPI, Basel, Switzerland. This article is an open access article distributed under the terms and conditions of the Creative Commons Attribution (CC BY) license (https:// creativecommons.org/licenses/by/ $4.0 /)$.

\begin{abstract}
A new data mining approach as a short cut method is given for the determination of the copolymer composition from mass spectra. Our method simplifies the copolymer mass spectra by reduction of the number of mass peaks. The proposed procedure, namely the selection of the mass peaks, which is based on the most abundant peak of the mass spectrum, can be performed manually or more efficiently using our recently invented Mass-remainder analysis (MARA). The considerable reduction of the MS spectra also simplifies the calculation of the copolymer quantities for instance the number- and weight-average molecular weights $\left(M_{n}\right.$ and $M_{w}$, respectively), polydispersity index $\left(Ð=M_{w} / M_{n}\right)$, average molar fraction $\left(c_{A}\right)$ and weight fraction $\left(w_{A}\right)$ of the comonomer $A$ and so on. These copolymer properties are in line with those calculated by a reference method taking into account all the mass peaks of the copolymer distribution. We also suggest a highly efficient method and template for the determination of the composition drift by processing the reduced mass spectra
\end{abstract}

Keywords: mass spectrometry; copolymers; data mining; Mass-remainder analysis

\section{Introduction}

For a thorough understanding of the influence of the copolymer structure on the copolymer properties, accurate and detailed characterization of the copolymer chains at molecular level is crucial. The soft ionization mass spectrometry techniques such as matrixassisted laser desorption/ionization (MALDI) [1,2] or electrospray ionization (ESI) [3] can give detailed information on the composition of the individual copolymer chains. However, the large number of $\mathrm{m} / \mathrm{z}$ peaks makes the evaluation of the mass spectra of copolymers difficult, time and labor-consuming. Although the application of coupled methods, such as HPLC-MS [4], LAC-MS [5], LACCC-MS [6], SEC-MS and IM-MS [7], decrease the complexity of a spectrum, the number of spectra to be evaluated increases significantly. The manual identification of hundreds or thousands of peaks is not feasible; hence, the compositional assignment of the individual copolymer molecules requires the use of computer software tools. Therefore, several data processing approaches and algorithms have been developed and implemented to determine the elemental composition of the numerous $\mathrm{m} / \mathrm{z}$ peaks of the copolymer mass spectra [8-13]. After all, some issues are not yet completely resolved: (i) many of the methods merely assign the chemical composition to the mass spectral peaks; however, they do not or only partly compute the essential copolymer quantities (e.g., the averaged molecular weights of the repeat units, the composition drift [14] and so forth); (ii) the implementation of the mass spectral processing algorithms requires special skills or software development experts; (iii) the general algorithms are not capable of handling the specific copolymer systems.

Recently, we developed the Mass-remainder analysis (MARA), which is capable of handling the mass spectra of copolymers, even those obtained by low-resolution mass 
spectrometer. The capability of our method was proved by analyzing copolymers [15], epoxidized vegetable oils [16], crude oil [17], copolymer blends [18] and even for the analysis of flavonoids [19]. The further development of such a filtering method is of paramount importance for the processing of complex mass spectra.

In this work, we report a new data mining approach, which significantly simplifies the copolymer mass spectra and consequently substantially reduces the required computational resources and speeds up the data-interpretation process. Nevertheless, it allows the accurate, reliable and comprehensive characterization of the copolymer mass spectra, for example, the construction of the compositional drift plots.

We demonstrate our new short cut data mining approach for copolymer analysis through the characterization of poly(ethylene oxide)-block-poly(propylene oxide)-blockpoly(ethylene oxide) (PEO-PPO-PEO) copolymers and the reversed $\mathrm{PPO}-\mathrm{PEO}-\mathrm{PPO}$ structures. These block copolymers have extensive industrial applications as surface active agents in detergency, cosmetics, pharmaceuticals and so on [20-22].

\section{Experimental}

\subsection{Chemicals}

The RPE2520, RPE1720-1, PE6100-1, PE6100-2, RPE1720-2, PE6200, RPE1740 and RPE3110 copolymers were gifts of BASF (Ludwigshafen, Germany). RPE1720-1 and PE6100-1 copolymers were acquired in 2006, RPE1720-2 and PE6100-2 were received in 2021. Pure water was produced by a Direct-Q system (Millipore, Molsheim, France). Methyl alcohol was obtained from VWR Chemicals (Leuven, Belgium). Table 1 shows the analyzed copolymers and their EO content.

Table 1. List of the analyzed copolymers. EO content is provided by the vendor.

\begin{tabular}{ccc}
\hline Name & EO Weight Fraction $\mathbf{( m / \mathbf { m }} \mathbf{\%})$ & Blocks \\
\hline RPE 2520 & 20 & PPO-PEO-PPO \\
RPE $1720-1$ & 20 & PPO-PEO-PPO \\
PE 6100-1 & 10 & PEO-PPO-PEO \\
PE 6100-2 & 10 & PEO-PPO-PEO \\
RPE 1720-2 & 20 & PPO-PEO-PPO \\
PE 6200 & 20 & PEO-PPO-PEO \\
RPE 1740 & 40 & PPO-PEO-PPO \\
RPE3110 & 10 & PPO-PEO-PPO \\
\hline
\end{tabular}

\subsection{Matrix-Assisted Laser Desorption/Ionization Time-of-Flight Mass Spectrometry}

An Autoflex Speed MALDI-TOF mass spectrometer (Bruker Daltonik, Bremen, Germany) was used for the MS analysis. The reflector mode was used with the voltages ionsource-1, ionsource-2, reflector-1 and reflector-2: $19 \mathrm{kV}, 16.65 \mathrm{kV}, 21 \mathrm{kV}$ and $9.55 \mathrm{kV}$, respectively. The spectrometer is equipped with a solid state laser $(355 \mathrm{~nm})$. Internal calibration was applied using various polyethylene oxides. The matrix was trans-2-[3-(4-tert-Butylphenyl)2-methyl-2-propenylidene] malononitrile (DCTB) and sodium trifluoroacetate (NaTFA) was used as an ionization agent. The concentrations of the samples, matrix and ionization agent were $10 \mathrm{mg} / \mathrm{mL}, 15 \mathrm{mg} / \mathrm{mL}$ and $5 \mathrm{mg} / \mathrm{mL}$, respectively (the solvent was methanol). The sample, matrix and ionization agent were mixed in the ratio of 2:5:1, individually.

\section{Results and Discussion}

Ethylene oxide (EO) — propylene oxide (PO)-based amphiphilic block copolymers—is widely used in the chemical industry. Their diverse applications emphasize the importance of the mass spectrometric characterization of these copolymers. Figure 1a depicts the MALDI-TOF mass spectrum of an amphiphilic PPO-PEO-PPO copolymer with $20 \mathrm{wt} \%$ ethylene oxide (EO) content and number-average molecular weight $\left(M_{n}\right)$ of approximately $2700 \mathrm{~g} / \mathrm{mol}$ (RPE2520). Additional MALDI-TOF MS spectra of triblocks with various 
number-average molecular weights and EO weight fractions are shown in Figures S1-S7 in the electronic supplementary material.
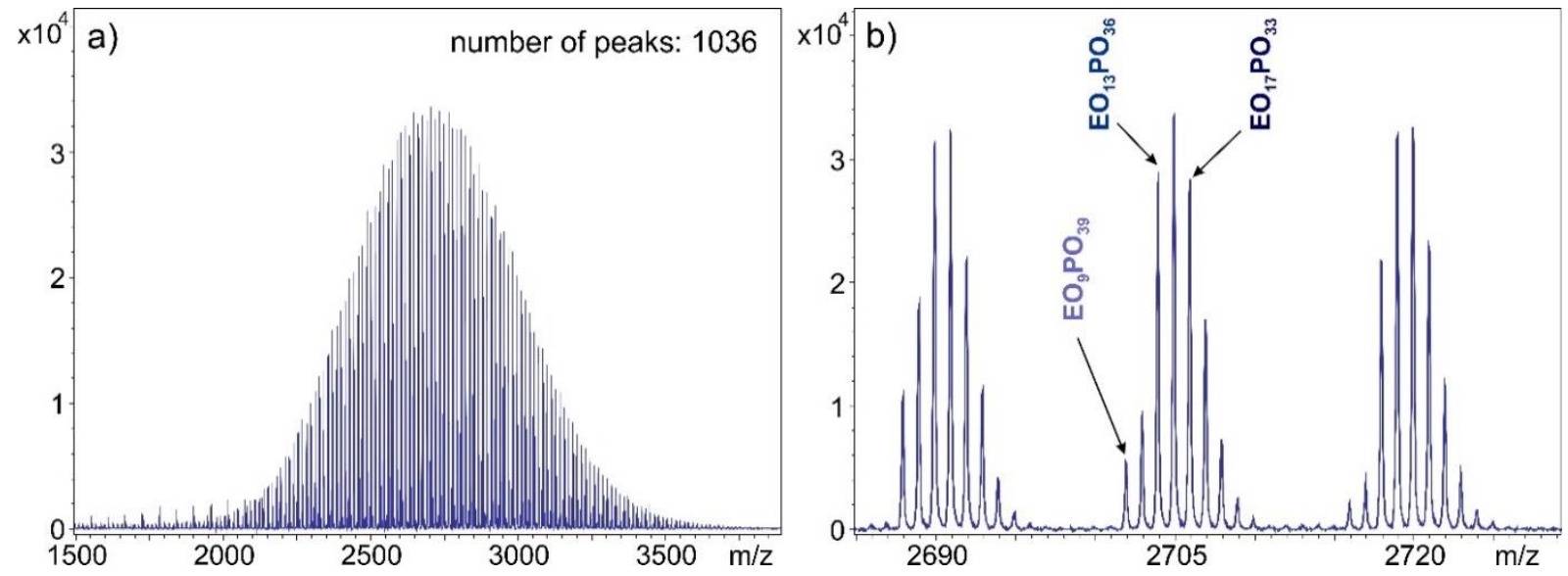

Figure 1. (a) MALDI-TOF mass spectrum of PPO-PEO-PPO copolymer with about $20 \mathrm{wt} \%$ EO content (RPE2520). (b) Zoomed MALDI-TOF mass spectrum showing the peak clusters around the most abundant peak.

The large number of mass peaks in Figure 1a proves the need for special algorithms or software for the evaluation of these complex mass spectra. Moreover, the zoom of each single line in the mass spectra reveals a peak cluster consisting of partially overlapped isotopic peaks of several $\mathrm{EO}_{\mathrm{n}} \mathrm{PO}_{\mathrm{m}}$ cooligomers (see Figure 1b), which make the interpretation of the spectra even more challenging. It is specific to the $\mathrm{EO} / \mathrm{PO}$ copolymers that $\mathrm{EO}_{\mathrm{n}} \mathrm{PO}_{\mathrm{m}}$ overlaps the second isotope of $\mathrm{EO}_{\mathrm{n}-4} \mathrm{PO}_{\mathrm{m}+3}$ (see e.g., $\mathrm{EO}_{17} \mathrm{PO}_{33}$ and $\mathrm{EO}_{13} \mathrm{PO}_{36}$ in Figure 1b).

The basic idea of our short cut method is the simplification of the copolymer mass spectrum, i.e., the reduction of the number of mass peaks with a minimal loss or distortion of information on the copolymer structure. The steps of our method are as follows:

(1) Selecting and identifying the most intense peak of the mass spectrum. The number of EO and PO units ( $n_{E O}$ and $n_{P O}$, respectively) of the most intense $m / z$ peak are determined by the Mass-remainder analysis (MARA) [15]. The mass remainder value $M R_{P O}$ is calculated using the exact mass of the propylene oxide comonomer $\left(\mathrm{C}_{3} \mathrm{H}_{6} \mathrm{O}=58.04187 \mathrm{Da}\right)$ as the base unit $R$ of the MARA division (Equation (1)):

$$
M R_{P O}=m / z \operatorname{MOD} R
$$

where MOD is the modulo operation.

Then, $n_{E O}$ can easily be obtained by the bijective $n_{E O}-M R_{P O}$ mapping and subsequently $n_{P O}$ can be calculated as detailed in our previous report [15]. For the mass spectrum presented in Figure 1 the composition of the most intense peak is $\mathrm{EO}_{13} \mathrm{PO}_{36}$.

(2) Reduction of the mass spectrum. The simplified mass spectrum contains only the $\mathrm{EO}_{x} \mathrm{PO}_{y}$ peaks corresponding to the condition $x=13$ or $y=36$, that are the $n_{E O}$ and $n_{P O}$ values of the most intense peak. This reduction is done by MARA filtering, as follows: Figure 2 shows the $M R_{P O}$ vs. $m / z$ and $M R_{E O}$ vs. $m / z$ plots of the mass spectrum presented in Figure 1a. $M R_{E O}$ can be obtained by a formula analogous to Equation (1), with the base unit $R=\mathrm{C}_{2} \mathrm{H}_{4} \mathrm{O}=44.02622$ Da. Each dot row represents an $\mathrm{EO}_{n} \mathrm{PO}_{x}$ series with constant $n$ values and an $\mathrm{EO}_{y} \mathrm{PO}_{m}$ series with constant $m$ values in Figure 2a,b, respectively. Accordingly, we reduce the mass spectrum keeping only two series: (a) $\mathrm{EO}_{13} \mathrm{PO}_{x}$, the peaks having $M R_{P O}$ values corresponding to $n_{E O}=13$ (see Figure $2 \mathrm{a}, M R_{P O}=32.92=(13 \times 44.02622+x \times 58.04187+40.99979)$ MOD 58.04187, where $\left[\mathrm{H}_{2} \mathrm{O}+\mathrm{Na}\right]^{+}=40.99979 \mathrm{Da}$ is the mass of the end group plus the ionizing agent) and (b) $\mathrm{EO}_{y} \mathrm{PO}_{36}$, the peaks having $M R_{E O}$ values corresponding to $n_{P O}=36$ (see Figure $2 \mathrm{~b}$ ). 
The reduced mass spectrum contains only two series, $\mathrm{EO}_{13} \mathrm{PO}_{x}$ and $\mathrm{EO}_{y} \mathrm{PO}_{36}$, represented by blue and red colors, respectively, (see Figure 3a.) As the peak numbers indicate (1036 of the original and 42 of the reduced), a remarkable reduction ratio (0.04) can be achieved.
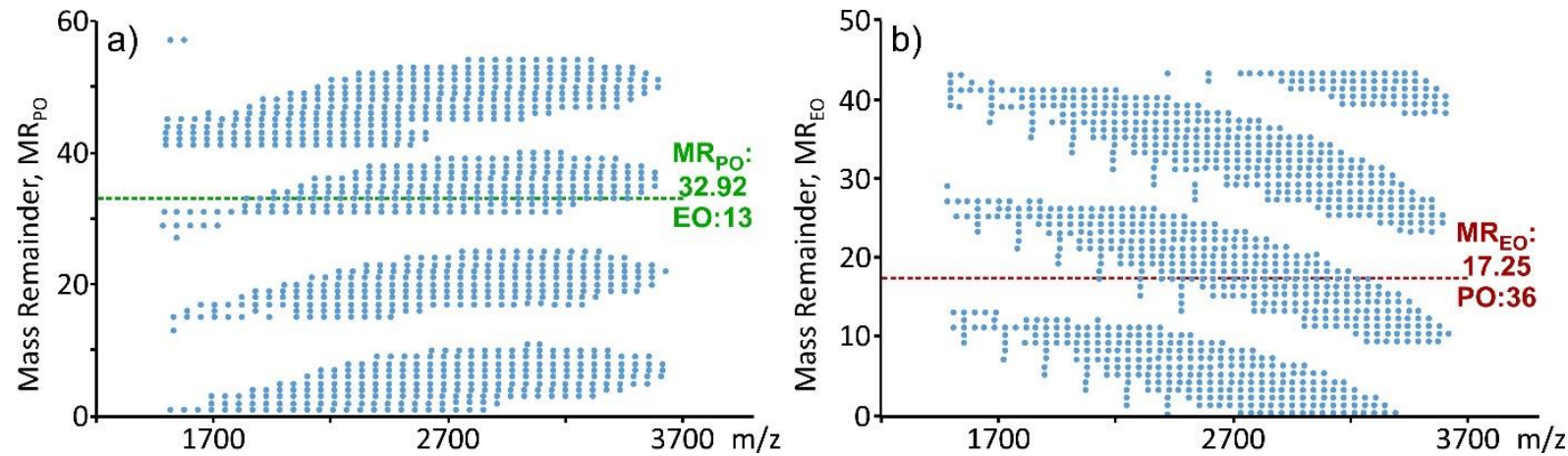

Figure 2. (a) The $M R_{P O}$ vs. $m / z$ and (b) $M R_{E O}$ vs. $m / z$ plots of the MALDI-TOF mass spectra of PPO-PEO-PPO copolymer with about $20 \mathrm{wt} \%$ EO content (RPE2520). The green and red horizontal lines illustrate the MARA filtering process.
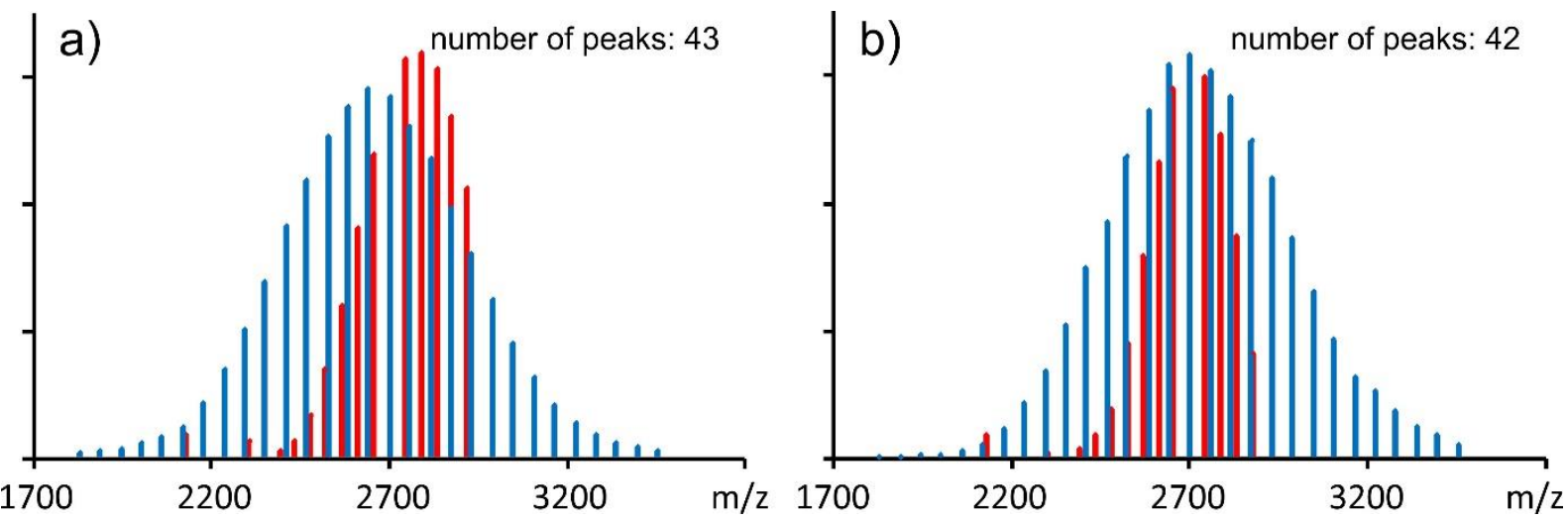

Figure 3. Simplified mass spectrum as the result of our data reduction method of the MALDI-TOF mass spectrum of PPO-PEO-PPO copolymer with about $20 \mathrm{wt} \%$ EO content (RPE2520) (a) before and (b) after intensity correction. $\mathrm{EO}_{13} \mathrm{PO}_{x}$ and $\mathrm{EO}_{y} \mathrm{PO}_{36}$ represented by blue and red colors, respectively.

(3) Intensity correction. Each peak of the reduced mass spectrum (Figure 3a) is a member of a peak cluster in the raw spectrum, each containing partially overlapped isotopic peaks, as seen in Figure 1b. Therefore, in order to compute valid copolymer quantities, the peak intensities of the reduced mass spectrum must be corrected to reflect the abundance of the polymer chains of various chemical compositions. This correction is an essential part of the MARA algorithm, as detailed in our previous paper [15]. The intensity corrections were made applying polynomial functions calculated from the natural abundance of ${ }^{13} \mathrm{C}$ and ${ }^{18} \mathrm{O}$ isotopes. The parameters of the polynomials are shown in the electronic supplementary material in Tables S1 and S2. Figure 3b shows the reduced mass spectrum after the intensity correction step.

(4) Statistical description of the copolymer composition. The significant reduction of the number of peaks also simplifies the calculation of the usual copolymer quantities such as the number-average and weight-average molecular weights $\left(M_{n}\right.$ and $\left.M_{w}\right)$, polydispersity index $\left(Ð=M_{w} / M_{n}\right)$, average molar fraction $\left(c_{A}\right)$ and weight fraction $\left(w_{A}\right)$ of repeat unit $A$, number-average number of comonomers $A$ and $B\left(n_{n}{ }^{A}, n_{n}{ }^{B}\right)$, weight-average number of comonomers $A$ and $B\left(n_{w}{ }^{A}, n_{w}{ }^{B}\right)$ and the polydispersity index for the repeat units $\left(\bigoplus_{A}=n_{w}{ }^{A} / n_{n}{ }^{A}, \bigoplus_{B}=n_{w}{ }^{B} / n_{n}{ }^{B}\right)$ [23], as it is exemplified in the electronic supporting material Short-Cut.xlsx. 
Furthermore, it is obvious that our short cut method is very effective in data reduction, but the essential question remains open as to whether the information on the copolymer structure is valid or distorted. To answer this question, various copolymer mass spectra were evaluated by two different ways: by this novel short cut method and by our recently invented and reported robust algorithm, as a reference method that is implemented into a homemade software [8]. The latter technique was validated by nuclear magnetic resonance (NMR) spectroscopy [8]. Table 2 contains the detailed chemical compositions of 8 industrially important EO/PO copolymers determined by both the short cut and the reference method used for processing their MALDI-TOF spectra.

Table 2. Chemical composition of various triblock copolymers determined by the short cut and the reference method [8].

\begin{tabular}{|c|c|c|c|c|c|c|c|c|c|c|c|c|}
\hline Name & $\begin{array}{l}\text { Process } \\
\text { Method }\end{array}$ & $\mathbf{M}_{\mathbf{n}}$ & $\mathbf{M}_{\mathbf{w}}$ & Đ & $\mathrm{c}_{\mathrm{EO}}$ & $\mathbf{w}_{\text {EO }}$ & $n_{n}{ }^{E O}$ & $\mathbf{n}_{\mathrm{w}}{ }^{\mathrm{EO}}$ & $\bigoplus_{\mathrm{EO}}$ & $\mathbf{n}_{n}{ }^{P O}$ & $\mathrm{n}_{\mathrm{w}}{ }^{\mathrm{PO}}$ & $\bigoplus_{\mathrm{PO}}$ \\
\hline \multirow{2}{*}{ RPE2520 } & reference & 2727 & 2758 & 1.011 & 0.256 & 0.207 & 12.6 & 13.2 & 1.05 & 36.7 & 37.2 & 1.01 \\
\hline & short cut & 2678 & 2694 & 1.006 & 0.259 & 0.210 & 12.7 & 13.3 & 1.04 & 36.6 & 37.1 & 1.01 \\
\hline \multirow{2}{*}{ RPE1720 } & reference & 2102 & 2142 & 1.019 & 0.299 & 0.241 & 11.4 & 12.2 & 1.06 & 26.8 & 27.5 & 1.03 \\
\hline & short cut & 2082 & 2102 & 1.010 & 0.299 & 0.245 & 11.7 & 12.4 & 1.06 & 26.7 & 27.4 & 1.03 \\
\hline \multirow{2}{*}{ PE6100 } & reference & 1801 & 1863 & 1.034 & 0.072 & 0.055 & 2.2 & 4.7 & 2.14 & 28.6 & 29.5 & 1.03 \\
\hline & short cut & 1623 & 1675 & 1.032 & 0.071 & 0.056 & 2.4 & 4.6 & 1.93 & 27.3 & 28.3 & 1.04 \\
\hline \multirow{2}{*}{ PE6100 } & reference & 1930 & 1975 & 1.023 & 0.091 & 0.071 & 3.0 & 5.4 & 1.78 & 30.2 & 30.9 & 1.02 \\
\hline & short cut & 1763 & 1799 & 1.020 & 0.091 & 0.071 & 3.2 & 5.4 & 1.70 & 29.6 & 30.6 & 1.03 \\
\hline \multirow{2}{*}{ RPE1720 } & reference & 2291 & 2324 & 1.015 & 0.300 & 0.245 & 12.5 & 13.3 & 1.06 & 29.2 & 29.7 & 1.02 \\
\hline & short cut & 2259 & 2274 & 1.007 & 0.302 & 0.248 & 12.8 & 13.4 & 1.05 & 29.2 & 29.9 & 1.02 \\
\hline \multirow{2}{*}{ PE6200 } & reference & 2528 & 2577 & 1.019 & 0.369 & 0.307 & 17.4 & 19.8 & 1.14 & 29.7 & 30.2 & 1.02 \\
\hline & short cut & 2431 & 2458 & 1.011 & 0.369 & 0.309 & 17.2 & 19.3 & 1.12 & 29.6 & 30.0 & 1.02 \\
\hline \multirow{2}{*}{ RPE1740 } & reference & 2445 & 2468 & 1.009 & 0.510 & 0.441 & 24.1 & 24.5 & 1.02 & 23.1 & 23.6 & 1.02 \\
\hline & short cut & 2389 & 2401 & 1.005 & 0.509 & 0.441 & 24.1 & 24.6 & 1.02 & 22.8 & 23.3 & 1.02 \\
\hline \multirow{2}{*}{ RPE3110 } & reference & 3440 & 3471 & 1.009 & 0.210 & 0.168 & 12.9 & 13.7 & 1.06 & 48.7 & 49.3 & 1.01 \\
\hline & short cut & 3402 & 3422 & 1.006 & 0.209 & 0.167 & 12.8 & 13.4 & 1.05 & 48.5 & 49.0 & 1.01 \\
\hline
\end{tabular}

Comparing the corresponding reference and short cut quantities in Table 2, it can be concluded that our short cut method correctly determines the composition of the Pluronictype triblock copolymers. For example, one of the most important parameters, the average molar fraction of the $\mathrm{EO}$ units $\left(c_{E O}\right.$, that fundamentally determines the micelle formation of the Pluronics necessary, e.g., for drug delivery systems) shows only $0.49 \%$ average relative difference between the Short cut $(S)$ and the reference $(R)$ values (calculated as the average of abs $(S-R) / R \times 100$ for all the eight triblock copolymers). Moreover, the paired two-sample t-test has determined that the mean difference between the corresponding $c_{E O}$ values is zero $(p=0.65)$.

For the comprehensive characterization of the copolymers, it is often necessary to determine-in addition to the distribution parameters summarized in Table 2-the variation of the composition with the polymer chain length, called the composition drift [14]. The number of peaks of the reduced mass spectrum (e.g., 42, see Figure 3) is not enough to construct the composition drift plot, but the original mass spectrum can be modelled ("restored") by constructing the outer product of the intensities of the two series of the reduced spectrum as two vectors. In our example, the $\mathrm{EO}_{13} \mathrm{PO}_{x}$ series has 29; the $\mathrm{EO}_{y} \mathrm{PO}_{36}$ series has 14 elements, resulting in a $29 \times 14$ outer product matrix. The construction of this model mass spectrum and the subsequent composition drift plot calculation can be easily implemented by a common spreadsheet application, as demonstrated in the electronic supporting material Short-Cut.xlsx. Figure 4 shows the composition drift plot of 
the PPO-PEO-PPO copolymer with about $20 \mathrm{wt} \%$ EO content (RPE2520) created by the reference and the short cut method.

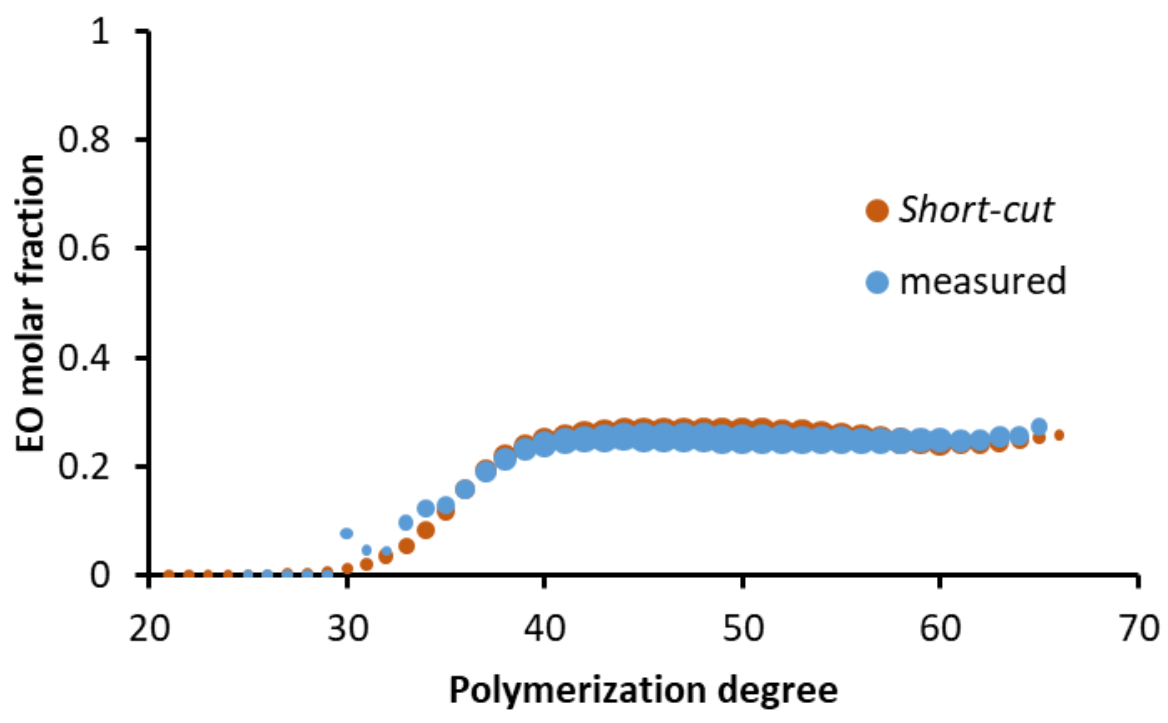

Figure 4. Composition drift plots of the PPO-PEO-PPO copolymer with about $20 \mathrm{wt} \%$ EO content (RPE2520) calculated by the short cut (red) and measured by the reference (blue) method. The size of the dots represents the sum of intensity correspond to each polymerization degree in logarithmic scale.

As seen in Figure 4, the curves constructed by the reference and short cut method coincides with each other, especially in the middle polymerization degree (PD) domain. The zero EO molar fraction in the low PD region, revealed by both methods, indicates the presence of $\mathrm{PPO}$ homopolymers in the copolymer sample. A small deviance in the range of 30-35 polymerization degrees is the result of higher intensity deviation of small intensity peaks as it turns out from the size of the dots in Figure 4. In this region the intensity of the peaks is close to the detection limit; thus, the acceptance or the decline of even one peak during the peak-picking has a high effect on the resulting EO molar fraction. The good agreement between the composition drift determined by the two methods justifies the capability of our short-cut method for copolymer analysis.

\section{Conclusions}

A novel, short cut method was proposed for processing of the copolymer mass spectra. The key was to considerably reduce the number of mass peaks in order to facilitate peak assignment and calculation of the characteristic copolymer parameters. Our method was tested by evaluating of the MALDI-TOF MS spectra of various EO/PO copolymers. It was concluded that the short cut method determines very well the compositional properties of the Pluronic-type triblock copolymers. The simplification of the mass spectra keeps only two series ( 42 peaks in the example of this paper) that can be identified and assigned manually or by our previously reported MARA method. A large benefit of our method is that all the subsequent calculations can be implemented in a common spreadsheet application in a very plain and straightforward way. The construction of the composition drift plot merely requires a sophisticated spreadsheet implementation, but we propose a "easy to follow and apply" template for it in the electronic supplementary material. The proposed short cut method can also be applied for the analysis of other copolymers.

Supplementary Materials: The following supporting information can be downloaded at: https: / / www.mdpi.com/article/10.3390/pr10010042/s1, Figure S1. MALDI-TOF mass spectrum of sample RPE-1720-1, Figure S2. MALDI-TOF mass spectrum of sample PE-6100-1, Figure S3. MALDI-TOF mass spectrum of sample PE-6100-2, Figure S4. MALDI-TOF mass spectrum of sample RPE-1720-2, Figure S5. MALDI-TOF mass spectrum of sample PE-6200, Figure S6. MALDI-TOF mass spectrum 
of sample RPE-1740, Figure S7. MALDI-TOF mass spectrum of sample RPE-3110, Table S1. The constants of the polynomials originated from the intensities of isotopic peaks as a function of $\mathrm{C}$ atom number., Table S2. The constants of polynomials originated from the intensities of isotopic peaks as a function of $\mathrm{O}$ atom number.

Author Contributions: Conceptualization; Á.K., S.K., T.N., methodology; Á.K., G.R., A.N., T.N., data curation; Á.K., G.R., A.N., T.N., formal analysis; Á.K., G.R., A.N., T.N., supervision; Á.K., M.Z., S.K., T.N., visualization; Á.K., G.R., T.N., roles/writing—original draft; Á.K., T.N., writing—review and editing; Á.K., M.Z., S.K., T.N. All authors have read and agreed to the published version of the manuscript.

Funding: The work was supported by the Thematic Excellence Program (TKP2020-NKA-04) of the Ministry for Innovation and Technology in Hungary and by the grant No. FK-132385 from National Research, Development and Innovation Office (NKFI). T.N. also acknowledge the János Bolyai Research Scholarship of the Hungarian Academy of Sciences (BO/00212/20/7) and ÚNKP-21-05-DE-476 from the New National Excellence Program of the Ministry for Innovation and Technology.

Institutional Review Board Statement: Not applicable.

Informed Consent Statement: Not applicable.

Data Availability Statement: Data is contained within the article or supplementary material.

Conflicts of Interest: The authors declare no conflict of interest.

\section{References}

1. Karas, M.; Hillenkamp, F. Laser desorption ionization of proteins with molecular masses exceeding 10,000 daltons. Anal. Chem. 1988, 60, 2299-2301. [CrossRef]

2. Tanaka, K.; Waki, H.; Ido, Y.; Akita, S.; Yoshida, Y.; Yoshida, T.; Matsuo, T. Protein and polymer analyses up to m/z 100000 by laser ionization time-of-flight mass spectrometry. Rapid Commun. Mass Spectrom. 1988, 2, 151-153. [CrossRef]

3. Wong, S.F.; Meng, C.K.; Fenn, J.B. Multiple charging in electrospray ionization of poly(ethylene glycols). J. Phys. Chem. 1988, 92, 546-550. [CrossRef]

4. Weidner, S.M.; Falkenhagen, J.; Bressler, I. Copolymer Composition Determined by LC-MALDI-TOF MS Coupling and “MassChrom2D" Data Analysis. Macromol. Chem. Phys. 2012, 213, 2404-2411. [CrossRef]

5. Pasch, H. Hyphenated separation techniques for complex polymers. Polym. Chem. 2013, 4, 2628-2650. [CrossRef]

6. Crotty, S.; Gerişlioğlu, S.; Endres, K.J.; Wesdemiotis, C.; Schubert, U.S. Polymer architectures via mass spectrometry and hyphenated techniques: A review. Anal. Chim. Acta 2016, 932, 1-21. [CrossRef]

7. Wesdemiotis, C. Multidimensional Mass Spectrometry of Synthetic Polymers and Advanced Materials. Angew. Chem. Int. Ed. 2017, 56, 1452-1464. [CrossRef]

8. Róth, G.; Nagy, T.; Kuki, Á.; Hashimov, M.; Vonza, Z.; Timári, I.; Zsuga, M.; Kéki, S. Polydispersity Ratio and Its Application for the Characterization of Poloxamers. Macromolecules 2021, 54, 9984-9991. [CrossRef]

9. Fouquet, T.; Sato, H. Extension of the Kendrick Mass Defect Analysis of Homopolymers to Low Resolution and High Mass Range Mass Spectra Using Fractional Base Units. Anal. Chem. 2017, 89, 2682-2686. [CrossRef]

10. Fouquet, T.N.J. The Kendrick analysis for polymer mass spectrometry. J. Mass Spectrom. 2019, 54, 933-947. [CrossRef]

11. Suen, W.; Percy, J.; Hsu, S.L.; Kaltashov, I.A.; Stidham, H.D. Influence of Polyether Copolymer Configuration on Polyurethane Reaction: A Mass Spectrometry Analysis. Cell. Polym. 2003, 22, 23-42. [CrossRef]

12. Terrier, P.; Buchmann, W.; Cheguillaume, G.; Desmazières, B.; Tortajada, J. Analysis of Poly(oxyethylene) and Poly(oxypropylene) Triblock Copolymers by MALDI-TOF Mass Spectrometry. Anal. Chem. 2005, 77, 3292-3300. [CrossRef] [PubMed]

13. Engler, M.S.; Crotty, S.; Barthel, M.J.; Pietsch, C.; Knop, K.; Schubert, U.S.; Böcker, S. COCONUT—An Efficient Tool for Estimating Copolymer Compositions from Mass Spectra. Anal. Chem. 2015, 87, 5223-5231. [CrossRef]

14. Montaudo, M.S.; Adamus, G.; Kowalczuk, M. Bivariate distribution in copolymers: A new model. J. Polym. Sci. Part A Polym. Chem. 2002, 40, 2442-2448. [CrossRef]

15. Nagy, T.; Kuki, Á.; Zsuga, M.; Kéki, S. Mass-Remainder Analysis (MARA): A New Data Mining Tool for Copolymer Characterization. Anal. Chem. 2018, 90, 3892-3897. [CrossRef] [PubMed]

16. Kuki, Á.; Nagy, T.; Hashimov, M.; File, S.; Nagy, M.; Zsuga, M.; Kéki, S. Mass Spectrometric Characterization of Epoxidized Vegetable Oils. Polymers 2019, 11, 394. [CrossRef]

17. Nagy, T.; Kuki, Á.; Nagy, M.; Zsuga, M.; Kéki, S. Mass-Remainder Analysis (MARA): An Improved Method for Elemental Composition Assignment in Petroleomics. Anal. Chem. 2019, 91, 6479-6486. [CrossRef] [PubMed]

18. Nagy, T.; Kuki, Á.; Hashimov, M.; Zsuga, M.; Kéki, S. Multistep Mass-Remainder Analysis and its Application in Copolymer Blends. Macromolecules 2020, 53, 1199-1204. [CrossRef] 
19. Nagy, T.; Róth, G.; Kuki, Á.; Zsuga, M.; Kéki, S. Mass Spectral Filtering by Mass-Remainder Analysis (MARA) at High Resolution and Its Application to Metabolite Profiling of Flavonoids. Int. J. Mol. Sci. 2021, 22, 864. [CrossRef]

20. Liu, T.; Wu, C.; Xie, Y.; Liang, D.; Zhou, S.; Nace, V.M.; Chu, B. Amphiphilic polyoxyalkylene triblock copolymers: Self-assembly, phase behaviors, and new applications. In Associative Polymers in Aqueous Media; American Chemical Society: Washington, DC, USA, 2000; Volume 765, pp. 2-20.

21. Yokoyama, M. Block copolymers as drug carriers. Crit. Rev. Ther. Drug Carrier Syst. 1992, 9, 213-248.

22. Edens, M.W. Applications of polyoxyalkylene block copolymer surfactants. In Nonionic Surfactants Polyoxyalkylene Block Copolymers; Nace, V., Ed.; Taylor \& Francis: Abingdon-on-Thames, UK, 1996; p. 26.

23. Van Rooij, G.J.; Duursma, M.C.; de Koster, C.G.; Heeren, R.M.A.; Boon, J.J.; Schuyl, P.J.W.; van der Hage, E.R.E. Determination of Block Length Distributions of Poly(oxypropylene) and Poly(oxyethylene) Block Copolymers by MALDI-FTICR Mass Spectrometry. Anal. Chem. 1998, 70, 843-850. [CrossRef] 